\title{
Hubungan Ketebalan Intima Media Arteri Karotis dan Massa Ventrikel Kiri pada Remaja Obes
}

\author{
David Kaunang, Irna Chandra, Stefanus Gunawan \\ Bagian/SMF Ilmu Kesehatan Anak Fakultas Kedokteran Universitas Sam Ratulangi / RS. Prof. Dr. R.D. Kandou, Manado
}

\begin{abstract}
Latar belakang. Obesitas pada anak berhubungan dengan peningkatan risiko kematian yang disebabkan aterosklerosis dan kardiomiopati pada saat dewasa. Ketebalan intima media (KIM) arteri karotis dan massa ventrikel kiri (MVK) adalah penanda awal aterosklerosis dan kardiomiopati yang dapat diperiksa sejak usia dini.

Tujuan. Mengetahui hubungan antara KIM arteri karotis dan MVK pada remaja obes.

Metode. Penelitian observasional analitik dengan pendekatan potong lintang terhadap 45 remaja usia 13-18 tahun dari bulan November 2013 - Februari 2014. Subyek dibagi menjadi obes dan tidak obes berdasarkan IMT menurut umur dan jenis kelamin. Penilaian KIM dan MVK dengan ekokardiografi. Pengolahan data dengan uji Mann-Whitney, uji t tidak berpasangan. Hubungan antara KIM dengan MVK ditentukan dengan uji regresi linier.

Hasil. Terdapat perbedaan bermakna antara KIM remaja obes (rerata 0,79 mm, SB 0,77) dibandingkan tidak obes (rerata $0,23 \mathrm{~mm}$, SB 0,22) (p<0,001). Rerata MVK remaja obes 456,75 g (SB 204,39) berbeda bermakna dengan rerata MVK tidak obes $138,24 \mathrm{~g}$ (SB 24,19) $(\mathrm{p}<0,001)$. Terdapat hubungan antara KIM dengan MVK pada remaja obes $(r=0,374 \mathrm{p}=0,006)$.

Kesimpulan. Ketebalan intima media arteri karotis dan MVK pada remaja obes berbeda bermakna dibandingkan tidak obes. Pada remaja obes terjadi peningkatan KIM dan MVK. Terdapat hubungan peningkatan KIM arteri karotis dengan peningkatan MVK pada remaja obes. Sari Pediatri 2015;17(4):249-54.
\end{abstract}

Kata kunci: ketebalan intima media, arteri karotis, massa ventrikel kiri, obesitas

\section{The relationship between Intima Media Thickness of Carotid Artery and Left Ventricular Mass in Obese Adolescents}

\author{
David Kaunang, Irna Chandra, Stefanus Gunawan
}

Background. Childhood obesity is associated with an increased risk of death due to atherosclerosis and cardiomyopathy in adulthood. Intima-media thickness (IMT) of carotid artery and left ventricular mass is an early marker of atherosclerosis and cardiomyopathy which can be checked at an early age.

Objective. To determine the relationship between IMT carotid artery and left ventricular mass in obese adolescents.

Method. Analytic observational study with cross sectional approach in 45 adolescents aged 13-18 years from November 2013 February 2014. The subjects were divided into obese and non obese group based on BMI for age and gender. The IMT and LVM were assessed with echocardiography. Data processing was done with the Mann-Whitney test, unpaired T test. The relationship between IMT and LVM in obese adolescents was determined with linear regression.

Results. There are significant differences of IMT in obese adolescents (mean $0.79 \mathrm{~mm}, \mathrm{SB} 0.77$ ) compared to non obese (mean 0.23 $\mathrm{mm}, \mathrm{SB}$ 0.22) $(\mathrm{p}<0.001)$. The IMT mean of obese adolescents $456.75 \mathrm{~g}$ (SB 204.39) was significantly different with non obese 138.24 $\mathrm{g}$ (SB 24.19) $(\mathrm{p}<0.001)$. There was a relationship between IMT and LVM in obese adolescents $(\mathrm{r}=0.374 \mathrm{p}=0.006)$.

Conclusion. Carotid artery intima-media thickness and LVM in obese adolescents are significantly different from obese adoloscents. Obese adoloscents have an increased IMT and LVM. There is a relationship between increased carotid artery IMT and LVM in obese adolescents. Sari Pediatri 2015;17(4):249-54.

Keywords: intima-media thickness, carotid artery, left ventricular mass, obesity

\footnotetext{
Alamat korespondensi: DR. Dr. Erling David Kaunang, SpA(K). Bagian Ilmu Kesehatan Anak FK Unsrat/RSU Prof,Dr.R.D.Kandou Manado Jl.Raya Tanawangko, Manado 95115, Sulawesi Utara. Tel. +62-431-821625. Fax. +62-431-859091, PO Box 66 Manado 95115. E-mail: drdavid kaunang@yahoo.com
} 


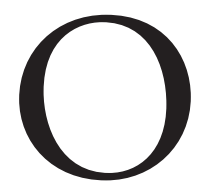
besitas merupakan keadaan kegemukan karena kelainan gizi yang berlebih. Pada keadaan ini, terjadi penimbunan jaringan lemak tubuh secara berlebihan yaitu indeks massa tubuh (IMT) menurut umur dan jenis kelamin lebih dari atau sama dengan persentil 95. ${ }^{1}$ Dewasa ini, peningkatan prevalensi obesitas tidak hanya di negara maju, tetapi juga di negara berkembang seperti Indonesia. Di Indonesia, angka prevalensi obesitas juga menunjukkan angka yang cukup mengkhawatirkan. Berdasarkan data SUSENAS tahun 2004, prevalensi obesitas pada anak telah mencapai $11 \%$. Berdasarkan data Riset Kesehatan Dasar (Riskesdas) tahun 2007, prevalensi nasional obesitas umum pada penduduk berusia $\geq 15$ tahun adalah $10,3 \%$ terdiri atas laki-laki $13,9 \%$ dan perempuan $23,8 \%$, sedangkan prevalensi overweight pada anak-anak usia 6-14 tahun pada laki-laki 9,5\% dan perempuan $6,4 \%$. Angka ini hampir sama dengan estimasi WHO yaitu 10\% pada anak usia 5-17 tahun. ${ }^{2}$ Data Riskesdas tahun 2010 memperlihatkan prevalensi obesitas anak usia sekolah (6-12 tahun) sebesar 9,2\%. Prevalensi obesitas pada anak laki-laki lebih tinggi dari anak perempuan (10,7\% dan 7,7\%). Berdasarkan tempat tinggal, daerah perkotaan lebih tinggi dibandingkan dengan pedesaan yaitu $(10,4 \%$ dan $8,1 \%) .^{3}$

Obesitas pada anak merupakan prediksi untuk terjadinya obesitas pada usia dewasa. Dilaporkan $15 \%$ obesitas pada bayi, $25 \%$ obesitas pada balita, dan $80 \%$ obesitas pada remaja akan menetap sampai dewasa. Prevalensi obesitas yang meningkat secara tidak langsung meningkatkan potensi penyakit kardiovaskular dan kematian akibat kardiovaskular pada orang dewasa. ${ }^{1,4}$

Beberapa penelitian menunjukkan bahwa kardiomiopati dan penyakit jantung koroner yang merupakan penyebab morbiditas dan mortalitas pada orang dewasa yang secara alamiah prosesnya terjadi sejak usia dini. ${ }^{5-7}$ Penelitian mengenai hubungan obesitas, ketebalan intima media (KIM) arteri karotis, dan massa ventrikel kiri (MVK) pada anak dan remaja masih sedikit dibandingkan dengan dewasa. ${ }^{8}$ Hariyanto $\mathrm{dkk}^{9}$ menyatakan bahwa pada remaja obes terjadi peningkatan KIM. Hanevold $\mathrm{dkk}^{10}$ mendapatkan bahwa terjadi peningkatan MVK pada anak obes. Tujuan penelitian kami untuk menilai KIM arteri karotis sebagai penanda aterosklerosis dini dan MVK pada remaja obes.

\section{Metode}

Penelitian observasional analitik dilakukan dengan desain potong lintang untuk mengetahui hubungan antara obesitas pada remaja dengan KIM arteri karotis dan MVK di Divisi Kardiologi Anak Departemen Ilmu Kesehatan Anak FK Universitas Sam Ratulangi (Unsrat) Manado, mulai bulan November 2013Februari 2014.

Subjek adalah anak remaja yang obes dan tidak obes, berusia 13-18 tahun, dan bersekolah di SLTP, SMU di Kecamatan Tuminting, Manado. Kriteria eksklusi meliputi penyakit jantung bawaan, penyakit jantung didapat, glomerulonefritis akut, sindrom nefrotik, obesitas endogen. Formulir persetujuan ditandatangani orang tua setelah bersedia dan setuju untuk ikutserta dalam penelitian. Dilakukan pencatatan identitas, pengukuran berat badan (BB), tinggi badan (TB), perhitungan indeks massa tubuh (IMT), dan pemeriksaan fisik. Indeks massa tubuh $\left(\mathrm{kg} / \mathrm{m}^{2}\right)$ adalah BB (kg) dibagi kuadrat TB $\left(\mathrm{m}^{2}\right)$, obesitas bila IMT menurut umur dan jenis kelamin lebih dari atau sama dengan persentil 95 Center for Disease Control and Prevention (CDC) 2000, sedangkan normal (tidak obes) bila IMT berada antara persentil 5-84. ${ }^{1}$ Pemeriksaan KIM arteri karotis kiri dan kanan dan MVK dengan menggunakan alat ekokardiografi.

Penilaian arteri karotis kanan dan kiri dilakukan dengan alat ultrasonografik Sonos 4500 dengan menggunakan transduser berfrekuensi $12 \mathrm{MHz}$. Bagian proksimal bulbus karotikus diidentifikasi terlebih dahulu, dan segmen arteri karotis yang terletak 10 $\mathrm{mm}$ di sebelah proksimal dipakai sebagai tempat pemeriksaan. Ketebalan intima media diukur dari tepi atas garis ekogenik pertama sampai tepi pertama garis ekogenik yang kedua. Kedua hasil pemeriksaan tersebut (kiri dan kanan) dirata-ratakan. Massa ventrikel kiri diukur dengan dua dimensi dan langsung dilakukan ekokardiografi M-mode sesuai kriteria The American Society of Echocardiography (ASE).

Data disajikan dalam bentuk rerata dan simpangan baku. Nilai KIM pada remaja obes dan tidak obes dibandingkan dengan menggunakan uji MannWhitney, sedangkan untuk membandingkan rerata MVK pada remaja obes dan tidak obes digunakan uji t tidak berpasangan. Analisis korelasi antara KIM arteri karotis dengan MVK menggunakan uji Pearson dan regresi linier sederhana. Data diolah dengan menggunakan program SPSS versi 22. Nilai signifikansi 
yang digunakan adalah $\mathrm{p} \leq 0,05$. Penelitian ini telah mendapat persetujuan dari komite etik Fakultas Kedokteran Univeritas Sam Ratulangi, Manado.

\section{Hasil}

Didapatkan 20 remaja obes, 25 remaja tidak obes.
Karakteristik kedua kelompok tertera pada Tabel 1.

Terdapat perbedaan bermakna antara KIM arteri karotis pada remaja obes dibandingkan dengan tidak obes $(\mathrm{p}<0,001)$, demikian juga MVK $(\mathrm{p}<0,001)$ (Tabel 2). Berdasarkan analisis regresi linier terdapat hubungan yang bermakna antara KIM arteri karotis dengan MVK pada remaja obes $(r=0,374 ; p=0,006)$ (Gambar 1).

Tabel 1. Karakteristik subjek penelitian

\begin{tabular}{lccc}
\hline Karakteristik & $\begin{array}{c}\text { Obesitas } \\
(\mathrm{n}=20)\end{array}$ & $\begin{array}{c}\text { Berat badan normal } \\
(\mathrm{n}=25)\end{array}$ & $\begin{array}{c}\text { Total } \\
(\mathrm{n}=45)\end{array}$ \\
\hline Umur (tahun, $\mathrm{n})$ & & & \\
$\quad 13-14$ & 4 & 6 & 10 \\
$>14-15$ & 2 & 5 & 7 \\
$>15-16$ & 9 & 3 & 7 \\
$>16-17$ & 4 & 2 & 3 \\
$>17-18$ & 1 & & \\
Jenis kelamin (n) & & 14 & 22 \\
$\quad$ Laki-laki & 8 & 11 & \\
Perempuan & 12 & $162,5(7,9)$ & \\
Tinggi badan (rerata (SB), cm) & $161,2(9,5)$ & $47,5(7,2)$ & \\
Berat badan (rerata (SB), kg) & $91,4(14,5)$ & $113,6(9,9)$ & \\
Tekanan darah sistolik (rerata (SB), $\mathrm{mmHg})$ & $122,5(14,09)$ & $73,2(8,5)$ & \\
Tekanan darah diastolik (rerata (SB), $\mathrm{mmHg})$ & $77(9,2)$ & & \\
\hline
\end{tabular}

Tabel 2. Perbedaan KIM dan MVK pada remaja obes dan tidak obes

\begin{tabular}{lccc}
\hline Variabel & Obes $(\mathrm{n}=20)$ & Tidak Obes $(\mathrm{n}=25)$ & $\mathrm{p}$ \\
\hline KIM $(\mathrm{mm})$ & & & \\
Rerata & 0,79 & 0,23 & \\
SB & 0,77 & 0,22 & \\
Median & 0,17 & 0,06 & \\
IK95\% & $(0,42-1,15)$ & $(0,14-0,33)$ & $<0,001^{*}$ \\
Minimum & 0,12 & 0,04 & \\
Maksimum & 2,05 & 0,64 & \\
MVK (g) & & & \\
Rerata & 456,75 & 138,24 & \\
SB & 204,39 & 24,19 & \\
Median & 411,50 & 138,00 & \\
IK95\% & $(361,08-552,41)$ & $(128,25-148,22)$ & $<0,001^{* *}$ \\
Minimum & 179,00 & 89,00 & \\
Maksimum & 889,00 & 175,00 & \\
\hline
\end{tabular}

* Uji Mann-Whitney

** Uji T tidak berpasangan 


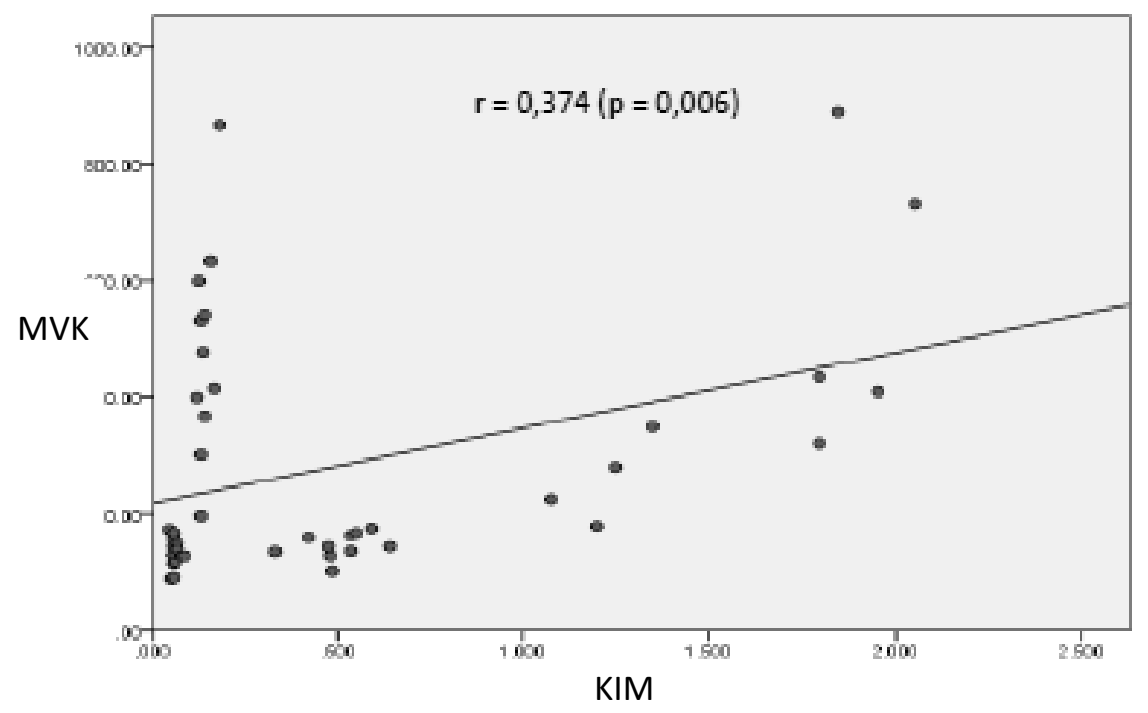

Gambar 1. Scatterplot hubungan KIM dan MVK pada remaja obes

\section{Pembahasan}

Pada penelitian kami, pengambilan sampel dilakukan pada remaja berumur 13-18 tahun berdasarkan penelitian sebelumnya yang melaporkan prevalensi obesitas akan meningkat pada rentang umur tersebut. Prevalensi obesitas pada anak usia 6-17 tahun dalam 3 dekade terakhir meningkat dari 10,8\% menjadi $14 \%$. Di Rusia, prevalensi obesitas pada anak usia 6-18 tahun adalah $10 \%$ dan di Cina 3,6\%. ${ }^{11}$

Kami mendapatkan remaja obes laki-laki lebih sedikit dari pada perempuan. Penelitian sebelumnya juga mendapatkan laki-laki lebih sedikit dari perempuan. ${ }^{12,13}$ Obesitas pada anak laki-laki lebih banyak terjadi dibandingkan perempuan karena pada anak perempuan akan terjadi peningkatan lemak tubuh sejak umur 4 tahun sehingga mereka mempunyai lemak tubuh yang lebih banyak daripada anak laki-laki tetapi peningkatan ini akan melambat setelah memasuki masa remaja. Sebaliknya, anak laki-laki berkembang terus sampai usia dewasa muda. ${ }^{14}$

Kami mendapatkan perbedaan bermakna rerata KIM arteri karotis pada remaja obes dan tidak obes $(0,79$ dan 0,23$) \mathrm{mm}$. Penelitian di Turki pada remaja yang tidak obes didapatkan rerata KIM $0,35 \mathrm{~mm}$ dibandingkan dengan $0,52 \mathrm{~mm}$ pada remaja obes. ${ }^{15}$ Hasil yang serupa juga didapatkan pada beberapa penelitian. ${ }^{16-18} \mathrm{Hal}$ tersebut menunjukkan bahwa remaja obes mempunyai rerata KIM yang lebih tebal dari remaja yang tidak obes. Sampai saat ini, cut off nilai KIM pada anak belum ditentukan. ${ }^{9}$ Obesitas pada masa anak, hipertensi, dan dislipidemia merupakan faktor risiko kardiovaskular yang memengaruhi perubahan aterogenik pada arteri. Hal tersebut menegaskan kejadian aterosklerosis early onset pada anak obesitas. ${ }^{8}$

Kami mendapatkan rerata MVK remaja obes 456,75 gram dan tidak obes 138,24 gram. Penelitian lain mendapatkan MVK remaja obes $165,03 \pm 41,07$ gram dibandingkan dengan tidak obes $131,78 \pm 30,15$ gram. ${ }^{19}$ Avelar $\mathrm{dkk}^{13}$ melaporkan rerata MVK remaja obes $234 \pm 65$ gram dibandingkan dengan tidak obes $160 \pm 38$ gram dan hubungan sinergis antara hipertropi ventrikel kiri dengan saturasi oksigen pada malam hari, tekanan darah, dan IMT. Obesitas menyebabkan peningkatan aktivitas saraf simpatis dibandingkan dengan tidak obes. ${ }^{20}$ Kami mendapatkan MVK jauh lebih tinggi dari penelitian terdahulu, hal ini mungkin pada penelitian kami rerata TD, BB, dan IMT lebih tinggi. Massa ventrikel kiri dipengaruhi ukuran tubuh, jenis kelamin, dan tekanan darah. ${ }^{19-21}$ Hasil penelitian kami menunjukkan hubungan positif antara KIM dengan MVK pada remaja obes. Beberapa penelitian sebelumnya mendapatkan hasil yang sama pada hubungan antara KIM dengan MVK ini. ${ }^{18,22-25}$

Aterosklerosis dapat menyebabkan gangguan fungsi diastolik selama episode iskemik awal, yaitu berupa gangguan relaksasi. Hal tersebut dapat disebabkan karena sejumlah miokard yang mengalami hipoksia akan mengalami peningkatan kekakuan 
atau penurunan kekenyalan sehingga mengakibatkan gangguan kekenyalan di ruang ventrikel secara keseluruhan. ${ }^{16,26}$ Pada anak obes, KIM arteri karotis berkorelasi positif dengan peningkatan tekanan darah. Selain itu, volume plasma yang meningkat juga akan menyebabkan curah jantung yang meningkat sehingga akan meningkatkan kerja dari ventrikel kiri dan menyebabkan peningkatan MVK. ${ }^{27,28}$

Desain potong lintang penelitian kami memiliki keterbatasan yaitu tidak dapat mengevaluasi dengan teliti faktor risiko lain yang menyebabkan peningkatan KIM dan MVK. Kami tidak meneliti faktor lama terpapar dengan obesitas karena lama terpapar dengan obesitas juga berpengaruh terhadap peningkatan KIM dan MVK. Pada penelitian ini, kami telah menanyakan sejak kapan anak tersebut mengalami obesitas, tetapi jawaban yang diberikan tidak terlalu jelas karena hanya berdasarkan mulai naiknya berat badan sehingga tidak dapat diketahui status gizi anak tersebut pada saat itu, apakah anak sudah obesitas atau overweight. Berdasarkan hal tersebut maka perlu dilakukan penelitian lanjut dengan desain kohort prospektif pada remaja obes untuk menilai peningkatan ketebalan KIM dan MVK.

Dari penelitian kami disimpulkan bahwa pada remaja obesitas terjadi peningkatan KIM arteri karotis dan MVK. Terdapat hubungan peningkatan KIM arteri karotis dengan peningkatan MVK pada remaja obes.

\section{Daftar pustaka}

1. Syarif DR. Obesitas anak dan remaja. Dalam: Sjarif DR, Lestari ED, Mexitalia M, Nasar SS, penyunting. Buku ajar nutrisi pediatrik dan penyakit metabolik. Jilid 1 . Jakarta: Badan Penerbit IDAI; 2011.h.230-44.

2. Riset Kesehatan Dasar (Riskesdas) tahun 2007. Depkes RI, Jakarta Tahun 2009.

3. Riset Kesehatan Dasar (Riskesdas) tahun 2010. Badan Penelitian dan Pengembangan Kesehatan Kementrian Kesehatan RI Tahun 2010.

4. Syarif DR, Nasar SS. Obesitas. Dalam: Pudjiadi AH, Hegar B, Handryastuti S, Idris NS, Gandaputra EP, Harmoniati ED, penyunting. Pedoman pelayanan medis ikatan dokter anak Indonesia. Jilid 1. Jakarta: Pengurus Pusat IDAI; 2010.h.197-204.

5. Dehghan M, Danesh NA, Merchant AT. Childhood obesity, prevalence and prevention: Review. Nutr J 2005;4:24-8.
6. Troxler RG, Park MK. Dyslipidemia and other cardiovascular risk factors. Dalam: Park MK, Troxler RG, penyunting. Pediatric cardiology for practitioners. Edisi 5. Philadelphia: Elsevier; 2008.h.427-40.

7. Lissau I. Prevention of overweight in the school arena. Acta Paediatr 2007;96:12-8.

8. Daniel SR. Coronary risk factors in children. Dalam: Allen HD, Driscoll DJ, Shaddy RE, Feltes TF, penyunting. Moss and Adams' heart disease in infants, children, and adolescents including the fetus and young adult. Edisi 7. Philadelphia: Lippincott Williams \& Wilkins; 2008.h.1448-75.

9. Hariyanto D, Madiyono B, Sjarif DR, Sastroasmoro S. Hubungan ketebalan tunika intima media arteri karotis dengan obesitas pada remaja. Sari Pediatri 2009;3:15966.

10. Hanevold C, Waller J, Daniels S, Portman R, Sorof J. The effect of obesity, gender and ethnic group on left ventricular hypertrophy and geometry in hypertensive children: a collaborative study of the international pediatric hypertension association. Pediatrics 2004;113:328-32.

11. Prentice AM. The emerging epidemic of obesity in developing countries. Int J Epidemiol 2006;35:93-9.

12. Friberg P, Johnson AA, Ambring A, Arheden H, Frame J. Increased left ventricular mass in obese adolescent. Eur Heart J 2004;25:987-92.

13. Avelar E, Cloward TV, Walker JM, Farney RJ, Strong M, Pendleton RC, dkk. Left ventricular hypertrophy in severe obesity.interactions among blood pressure, nocturnal hypoxemia, and body mass. Hypertension 2007;49:349.

14. Steinbeck K. Childhood obesity: consequences and physical and psychosocial complications. Dalam: Kopelman PG, Caterson ID, Dietz WH, penyunting. Clinical obesity in adults and children. Massachusetts: Blackwell Publishing, 2005.h.231-48.

15. Simsek E, Balta H, Balta Z, Dallar Y. Childhood obesityrelated cardiovascular risk factors and carotid intimamedia thickness. Turk J Pediatr 2010;52:602-11.

16. Reinehr $\mathrm{T}$, Wunsch $\mathrm{R}$. Intima media thickness-related risk factors in childhood obesity. Int J Pediatr Obes 2011;1:46-52.

17. Iannuzzi A, Licenziati MR, Acampora C. Increased carotid intima-media thickness and stiffness in obese children. Diabetes Care 2004;27:2506-8.

18. Stabouli S, Kotsis V, Karagianni C, Zakopoulos N, Konstantopoulos A. Blood pressure and carotid artery intima-media thickness in children and adolescents: the role of obesity. Hellenic J Cardiol 2012;53:41-7. 
19. Chinali M, Simone G, Lee ET, Roman M.1. Best LG, Howard BV, dkk. Impact of obesity on cardiac geometry and function in a population of adolescent. The Strong Heart Study. J Am Coll Cardiol 2006; 47:2267-73.

20. Kaufmann CL, Kaiser DR, Steinberg J, Kelly AS, Dengel DR. Relationship of cardiac autonomic function with metabolic abnormalities in childhood obesity. Obesity 2007; 15:1164-71.

21. Gidding SS. Clinical and epidemiological significance of left ventricular mass assessed in children and adolescents. Circulation 1998;97:1893-4.

22. Sameer K. Mehta, J. Eduardo Rame, Amit Khera, Sabina A. Murphy, dkk. Left Ventricular Hypertrophy, Subclinical Atherosclerosis, and Inflammation. Hypertension 2007;49:1385-91.

23. Zheng YX, Ying L, Jie M, Shu TC, Bao DJ. Pre-clinical atherosclerosis evaluated by carotid artery intima media thickness and the risk factors in children. Chin Med J 2007;120:359-62.

24. Sert A, Pirgon O, Aypar E, Yilmaz H, Odabas D. Relationship between left ventricular mass and carotid intima media thickness in obese adolescents with non alcoholic fatty liver disease. J Pediatr Endocrinol Metabol 2012;25:927-34.

25. Sorof JM, Alexandrov AV, Cardwell G, Portman RJ. Carotid artery intimal-media thickness and left ventricular hypertrophy in children with elevated blood pressure. Pediatrics 2003;111;61-5.

26. Guyton AC, John E. Atherosclerosis. Dalam: Guyton AC, John E, penyunting. Textbook of medical physiology. Edisi 11. Philadelphia: Elsevier; 2006. h. 848-51.

27. Steinberger J, Daniels SR. Obesity, insulin resistance, diabetes, and cardiovascular risk in children. An American heart association scientific statement from the atherosclerosis, hypertension, and obesity in the young committee (council on cardiovascular disease in the young) and the diabetes committee (council on nutrition, physical activity, and metabolism). Circulation 2009; 119:628-47.

28. Fruchart JC, Nierman MC, Stroes ESG, Kastelein JJP, Duriez P. New risk factors for atherosclerosis and patient risk assessment. Circulation 2004;109:15-9. 